\title{
Experiência de Gestão no CREAS em Interlocução com a Análise Institucional
}

\author{
Caroline de Souza ${ }^{1}$ \\ ${ }^{1}$ Pontifícia Universidade Católica de Minas Gerais, \\ Belo Horizonte, $M G$, Brasil.
}

\author{
Roberta Carvalho Romagnoli ${ }^{1}$ \\ ${ }^{1}$ Pontifícia Universidade Católica de Minas Gerais, \\ Belo Horizonte, $M G$, Brasil.
}

Resumo: Este texto tem como objetivo refletir acerca da experiência em um cargo de gestão do Centro de Referência Especializado de Assistência Social (CREAS) de uma cidade de grande porte de Minas Gerais, por meio do exame de suas possibilidades instituintes. A reflexão sobre a experiência parte de um processo de supervisão seguido de intervenções realizadas com os(as) técnicos(as) do serviço, com base nas trocas oriundas das reflexões entre teoria e prática. A partir das ideias de René Lourau sobre a Análise Institucional, examinamos a dinâmica institucional presente em cada situação problema e o jogo de forças opostas que se enunciam em contradições nas práticas cotidianas. Além disso, utilizamos concepções de Deleuze e Guattari para pensar os modelos presentes e as linhas de invenção que surgiram entre os profissionais. No percurso, destacamos a separação dos(as) técnicos(as) por núcleo, o que perpassa o trabalho de gestão e a própria atuação no CREAS, atuação que é aqui tratada como um analisador. As conclusões apontam para a importância de empreender leituras institucionais na atuação das equipes na Política de Assistência Social em direção a ações coletivas, pois a atuação do psicólogo ainda apresenta uma série de desafios nesse contexto.

Palavras-chave: Análise Institucional, Proteção Social Especial, CREAS.

\section{Management Experience in CREAS in Dialogue with Institutional Analysis}

\begin{abstract}
This article discusses the management experience in a Specialized Referral Center for Social Assistance (CREAS) from a large city of Minas Gerais, examining its instituting possibilities. To this end, we supervised and performed interventions with the service technicians considering the exchanges between theory and practice. The institutional dynamics in each problem-situation and the opposing forces in contradictions seen in everyday practices were examined in the light of the Institutional Analysis, as discussed by René Lourau. Moreover, the present models and invention lines emerging among professionals were thought through the ideas of Deleuze and Guattari. We verified the division of technicians into nuclei, which crosses the management work and their performance in CREAS, being thus consider as an analyzer. The results indicate the importance of Social Assistance Policy towards collective actions in sustaining institutional readings in team performance, as the psychologist's performance still meets a series of challenges in this context.
\end{abstract}

Keywords: Institutional Analysis, Special Social Protection, CREAS. 


\title{
Experiencia de Gestión en CREAS en Diálogo con el Análisis Institucional
}

\begin{abstract}
Resumen: Este texto pretende reflexionar sobre la experiencia en una posición gerencial del Centro de Referencia Especializado en Asistencia Social (CREAS) en una gran ciudad de Minas Gerais (Brasil), examinando sus posibilidades instituyentes. La reflexión sobre la experiencia se inicia con un proceso de supervisión y presenta intervenciones realizadas con los/as técnicos/ as del servicio a partir de los intercambios que surgen de estas reflexiones entre la teoría y la práctica. A partir de las ideas de René Lourau sobre el Análisis Institucional, se analizan las dinámicas institucionales presentes en cada situación problemática y el conjunto de fuerzas opuestas que se enuncian en contradicciones en las prácticas cotidianas. Además, se utiliza el pensamiento de Deleuze y Guattari para pensar los modelos actuales y las líneas de invención que surgieron entre los profesionales. En el camino, se destaca la separación de los/as técnicos/ as por núcleos que recorre el trabajo de gestión y el propio desempeño de CREAS, tratándolo como un analizador. Se concluye que es importante mantener las lecturas institucionales en el desempeño de los equipos de la Política de Asistencia Social hacia las acciones colectivas, ya que el desempeño del psicólogo todavía presenta una serie de desafíos en este contexto.
\end{abstract}

Palabras clave: Análisis Institucional, Protección Social Especial, CREAS.

\section{Introdução: apontamentos sobre a Psicologia na Assistência Social}

A Psicologia está cada vez mais presente no campo da política de Assistência Social. Macedo et al. (2011) chamavam a atenção para o grande número de profissionais que atuam na área. $\mathrm{Na}$ época do estudo, 8.079 psicólogos(as) atuavam no Sistema Único de Assistência Social (SUAS), dos quais 6.022 estavam inseridos em Centros de Referência em Assistência Social (CRAS) e 2.057, em Centros de Referência Especializado em Assistência Social (CREAS), números que certamente hoje se encontram ampliados. Nesse contexto, são inúmeros os desafios que permeiam a prática desses agentes sociais: a falta de formação, a dificuldade de trabalhar com as famílias, a pouca referência para atuar com a vulnerabilidade, dentre outros. Raichelis e Nery (2014) destacam ainda a ausência, nos currículos de graduação em Psicologia, de atividades acadêmicas e de disciplinas direcionadas para o conhecimento da política de assistência social e do SUAS. As autoras apontam que a produção mais significativa sobre a área tem sido abastecida pelos programas de pós-graduação e algumas linhas de pesquisa, na tentativa de auxiliar esses agentes em seu cotidiano.
Com a crescente entrada dos(as) psicólogos(as) no SUAS, Florentino e Melo (2017) argumentam que precisamos confrontar-nos com um processo de ressignificação de nosso exercício profissional, por meio da revisão de nossa relação com a vulnerabilidade social e da desconstrução de concepções instituídas e atuações cristalizadas, para abrir-nos à manifestação da descoberta, do acontecimento, uma vez que os modelos de trabalho e atuação nessa política estão em construção. Isso porque, até a implantação do SUAS, as referências ou sistematizações eram praticamente inexistentes, seja para o fornecimento de subsídios à atuação do psicólogo, seja para a elaboração de metodologias de intervenção.

Assim, a Psicologia é convocada a se inserir no campo das políticas sociais pela abertura para os profissionais no setor do bem-estar. Essa inserção convoca a categoria a uma certa revisão de sua atuação, fazendo com que profissionais e pesquisadores reavaliem seus modelos e suas concepções da Psicologia (Ribeiro, Paiva, Seixas, \& Oliveira, 2014).

Com o SUAS há a necessidade da consolidação da identidade do psicólogo como trabalhador da proteção social, o que apontaria a importância de mudanças no corpo conceitual e técnico da Psicologia e uma discussãow sobre a abrangência do 
seu trabalho profissional (Ribeiro, Paiva, Seixas, \& Oliveira, 2014, p. 465).

Ao examinar as práticas da Psicologia nas políticas de saúde e de assistência social, Marques, Roberto, Gonçalves e Bernardi (2019) evidenciam sua preocupação com o esvaziamento dos conceitos de território e vulnerabilidade, que favorece o enfraquecimento dessas políticas. Ao trabalhar em territórios que são não somente espaços geográficos, mas também espaços de vida, em que há relações de troca, vínculos e grande vulnerabilidade, a assistência social opera a proteção social e produz os usuários e as famílias, que passam a ser vistas como precárias. Nesse sentido, as práticas psi podem favorecer o controle dessas pessoas e dos próprios profissionais, e um dos vetores para isso é, no nível micropolítico, a individualização das questões sociais. Vivemos nos últimos quatro anos um processo de desmantelamento das políticas sociais públicas, marcado por tecnologias sociais que investem na morte e aumentam as desigualdades sociais. Nesse cenário, precisamos achar brechas para resistir e expandir nossos modos de viver e de trabalhar, na medida em que os profissionais atuantes na assistência social precisam ser capazes de garantir direitos humanos, com intervenções e práticas fundamentadas política e cientificamente (Silva, Vasconcellos, \& Figueiredo, 2018).

Nesse contexto, entendemos que a experiência tratada neste texto pode contribuir com a discussão, pois as normas instituídas da política de assistência social consideram a Psicologia como uma profissão que obrigatoriamente deverá estar presente nas equipes de referência de seus serviços. Nesse sentido, é inquestionável a importância dos recursos humanos para que os objetivos dessa política sejam cumpridos, pois o SUAS não opera por procedimentos substitutivos. Na verdade, como pontuam Florentino e Melo (2017), é por meio do trabalho social realizado pelas equipes de referências que se concretizam as diretrizes anunciadas pelos diversos documentos normativos.

O CREAS, equipamento no qual se localiza a experiência apresentada neste artigo, é uma unidade pública da política de Assistência Social onde são atendidas famílias e pessoas que estão em situação de risco social ou tiveram seus direitos violados, de modo que se localiza na Proteção Social Especial que tem como objetivo principal contribuir para a prevenção de agravamentos e potencialização de recursos para o enfrentamento de situações que envolvam risco pessoal e social, violência, fragilização e rompimento de vínculos familiares, comunitários e/ou sociais. Nesse sentido, algumas situações podem ser aqui elencadas: violência física, psicológica e negligência; abandono; violência sexual; situação de rua; trabalho infantil; cumprimento de medidas socioeducativas em meio aberto; afastamento do convívio familiar, dentre outras (Ministério do Desenvolvimento Social e Combate à Fome [MDS], 2011, p. 7).

A partir dessas orientações, a Proteção Social Especial é dividida em dois níveis de proteção: Média Complexidade e Alta Complexidade. A Proteção Social Especial de Média Complexidade organiza a oferta de serviços, programas e projetos de caráter especializado, por meio dos quais promove maior estruturação operativa e técnica, com competências e atribuições definidas, com foco no atendimento às famílias e aos indivíduos em situação de risco pessoal e social por violação de direitos. Dessa maneira, a oferta na Proteção Social Especial de Média Complexidade solicita acompanhamento especializado, individualizado, continuado e articulado à rede assistencial, devido à natureza e ao agravamento dos riscos pessoais e sociais vivenciados pelas famílias e indivíduos atendidos (Ministério do Desenvolvimento Social [MDS], 2017). No âmbito de atuação da Proteção Social Especial de Média Complexidade, constituem unidades de referência para a oferta de serviços o CREAS e o Centro de Referência Especializado para População em Situação de Rua (Centro POP).

Nesse nível da política, oferece-se obrigatoriamenteProteção eAtendimento Especializado a Família e Indivíduos (PAEFI), mas pode-se também disponibilizar o serviço para Pessoas com Deficiência, Idosas e suas famílias, bem como o Serviço Especializado em Abordagem Social, para pessoas em situação de rua. Em suas atividades, também consta o serviço de Medidas Socioeducativas em Meio Aberto, para adolescentes em conflito com a lei.

A Proteção Social Especial de Alta Complexidade, por sua vez, tem como objetivo ofertar serviços especializados, em diferentes equipamentos e modalidades, com vistas a afiançar segurança de acolhida a 
indivíduos e/ou famílias afastados temporariamente do núcleo familiar e/ou comunitário.

As ações que constituem o trabalho social no serviço a serem realizadas pelos profissionais do CREAS são: acolhida; estudo social; análise socioeconômica; acompanhamento, monitoramento e avaliação do serviço. Além disso, cabe também encaminhamentos para a rede de serviços locais, orientação, construção de um plano familiar e individual de atendimento, apoio na função protetiva das famílias, orientação jurídica, defesa dos direitos, acesso à documentação pessoal, mobilização, identificação da família extensa ou ampliada; articulação da rede de serviços socioassistenciais; articulação com os serviços de outras políticas públicas setoriais; articulação interinstitucional com os demais órgãos do Sistema de Garantia de Direitos; trabalho interdisciplinar e intersetorial; elaboração de prontuários individuais e relatórios, mobilização e fortalecimento do convívio familiar e comunitário, das redes sociais de apoio; dentre outras (MDS, 2011).

Nesse contexto, a gestão e o acompanhamento são também desafios para a Psicologia, que envolvem assistência às famílias, relações com o poder judiciário e encaminhamentos, além do próprio trabalho social, como vimos acima. $\mathrm{O}$ trabalho de gestão é também pautado por normativas e orientações da política de assistência social, na medida em que sustenta uma relação hierárquica na qual cabe supervisionar os(as) técnicos(as) nos acompanhamentos às famílias, exercer a intersetorialidade com o trabalho em rede e atentar-se a protocolos internos e regimentos. Esse cargo deve ainda coordenar o funcionamento da unidade, assegurar que as ações implementadas no CREAS sejam pautadas em referenciais teórico-metodológicos compatíveis com as diretrizes do SUAS, garantir o planejamento das ações, o registro de dados, o monitoramento das atividades institucionais, contribuir para o estabelecimento de fluxos entre os serviços de Proteção Social Básica e Especial de Média e Alta Complexidade, participar de conselhos de direitos e reuniões periódicas junto ao colegiado e gestão, realizar reuniões semanais com toda a equipe da unidade e com cada núcleo para a elaboração do planejamento, controle, avaliações e ajustes que se fizerem necessários e coordenar a execução das atividades administrativas da unidade.

Essas atividades também trazem uma série de desafios para o gestor, neste caso, com formação em psicologia. Os impasses vividos na gestão do CREAS versam sobre o manejo técnico, as intervenções com às famílias, a necessidade de uma postura ético-política na discussão de casos e uma atitude reflexiva sobre a própria gestão do serviço, dentre outros. Ressaltamos o sentido analítico e tensionador dessa postura, que, de acordo com Guattari (1993), refere-se ao exercício do pensamento que busca situações e acontecimentos como potencializadores ou não da vida, por meio do mapeamento dos planos de forças presentes nas situações e da análise dos efeitos produzidos e dos deslocamentos da realidade, para produzir outros modos de inserção na política de assistência social.

Nesse cenário, podemos nos perguntar: como convocar a cooperação nos modos de organização do CREAS e como potencializar as equipes em direção a práticas instituintes e potentes? Buscamos tentativas de respostas a essa questão a partir da leitura da dinâmica institucional presente em cada situação problema, que sustenta o jogo de forças opostas enunciadas em contradições nas práticas cotidianas, ou seja, analisadores, como denominado por Lourau (2004), que perpassam o trabalho de gestão e a própria atuação desenvolvida no CREAS. Para o referido autor, o analisador refere-se a uma situação, um acontecimento ou uma prática que revela o campo de forças institucionais e que expressa seu movimento, não apenas de reprodução, mas também de transformação (Lourau, 2004). Atentas aos analisadores, relatamos, a seguir, como conhecemos e refletimos acerca de nossa experiência a fim de embasar nossas intervenções para produzir deslocamentos em nós mesmos e na equipe.

\section{Sobre a metodologia de reflexão e intervenção}

Este relato de experiência trata de uma prática discutida e construída em supervisão por meio da lente da Análise Institucional de René Lourau, bem como do diálogo com as ideias de Gilles Deleuze e Félix Guattari. De acordo com Romagnoli (2014), essa associação é comumente feita pelos institucionalistas em nosso país, que sustentam práticas e pesquisas atentas ao posicionamento ético-político, às reinvindicações de nosso tempo e à realidade institucional e seus tensionamentos.

As demandas levadas à supervisão foram elaboradas a partir de relatos situacionais da equipe do 
CREAS feitos pela gestão, cargo assumido há quase três anos pela primeira autora em uma cidade de grande porte em Minas Gerais. A partir dessas situações, construímos um diálogo entre a teoria e a prática, sustentando indagações e buscando a intercessão entre as forças instituídas e as forças instituintes, o que nos permitiu ver o CREAS em seu processo dialético, no qual coexistem a manutenção do que já existe e a emergência de novas propostas e atuações. Essas duas forças, o instituído e o instituinte, estão presentes na política de assistência social e atravessam o cotidiano do equipamento em que estamos inseridos, "formando a trama social que une e atravessa os indivíduos, os quais, por meio de sua práxis, mantêm ditas instituições e criam outras novas (instituintes)" (Lourau, 2004, p. 68). Nesse processo, é preciso salientar que somos nós que criamos os serviços da política em questão, em movimentos instituintes, e também seguimos sustentando o instituído, apesar de muitas vezes termos a impressão de que a instituição existe autonomamente e devemos somente nos adaptarmos a ela. Afinal, não podemos nos esquecer que:

primeiro, as instituições são normas. Mas elas incluem também a maneira como os indivíduos concordam, ou não, em participar dessas mesmas normas. As relações sociais reais, bem como as normas sociais, fazem parte do conceito de instituição. Seu conteúdo é formado pela articulação entre a ação histórica de indivíduos, grupos, coletividades, por um lado, e as normas sociais já existentes, por outro (Lourau, 2004, p. 71).

Dessa maneira, embora o CREAS opere por normas, esse equipamento também se sustenta no modo como os profissionais se relacionam entre si, em suas atuações e no fato de os usuários corresponderem a um processo de deslocamentos e invenções, que ora encontra-se mais cristalizado, mais governado pelo instituído, como no início desta experiência, ora está mais propenso a experimentações e à emergência de forças instituintes, como veremos neste texto. Ou seja, esse processo de institucionalização em que coexistem contraditoriamente a manutenção e a criação, possibilita que o CREAS se construa continuamente "com" e "para" os indivíduos, convocando a Psicologia a ocupar esse espaço e também construir novas práticas.

Por meio desse olhar, buscamos nas situações institucionais que envolvem a relação da gestão com a equipe e da equipe com os usuários, analisadores, acontecimentos e práticas que denunciam os conflitos entre essas forças e cuja emergência ou elaboração podem levar à mudança daquela realidade, apostando nos profissionais que produzem e são produzidos pelas práticas cotidianas de qualquer serviço, neste caso, o CREAS. A atenção ao analisador é essencial no processo de conhecimento da instituição, pois, como nos lembra Lourau (1980, p. 156), "o analisador desinstitucionaliza, revela o instituinte achatado embaixo do instituído, e ao fazê-lo, desordena o instituído". Na verdade, a força do instituído sempre quer ocultar as contradições e conflitos, a fim de que elas façam parte do "não-dito" institucional que opera para a manutenção institucional. Desse modo, o "não-dito" corresponde a uma repressão, a uma censura à vontade de mudar da força instituinte. Contudo, essas tensões sempre aparecem, pois o processo de institucionalização é dialético, processual e o conflito, em sua emergência, pode promover transformações.

Outro elemento que nos permite acessar o "não-dito", além dos analisadores, é a própria implicação. Com base em pressupostos da Análise Institucional, o conceito de implicação corresponde ao que nos liga à instituição, isto é, diz de nossas pertenças e referências institucionais, e mostra que aquilo que a instituição deflagra em nós é sempre efeito de uma produção coletiva, de valores, interesses, expectativas, desejos e crenças que circulam nessa relação (Romagnoli, 2014). A implicação é ainda um conceito que associa as ideias institucionalistas, em nosso país, conectando-se com as ideias de Deleuze e Guattari, mesmo com diferenças epistemológicas como nos lembra Romagnoli (2014) ao apontar que ela efetua uma desestabilização entre essas vertentes na busca da complexidade e da transformação. Nesse sentido, os efeitos deflagrados são entendidos de formas distintas, pois, para Lourau (2004), a partir de um raciocínio dialético, eles emergem na realidade estudada por meio dos conflitos denunciados pelos analisadores; já para Deleuze \& Guattari (1996), a realidade é abordada por imanência e exterioridade e os efeitos emergem do plano de forças e das linhas que compõem esse plano. Atentas a esses efeitos, realizamos a análise da implicação, examinando o lugar que ocupamos em nosso trabalho, em nossas relações sociais, em espaços distintos do cotidiano. Como ressaltam Nascimento e Coimbra (2008), encontrar um método de análise da implicação trata-se de situar-se nas 
relações de poder, em vez de nos cristalizarmos numa posição pretensamente neutra.

Os espaços institucionais a priori são espaços de reprodução do instituído, de modo que cabe, nesse contexto, colocar em análise o lugar de nossas práticas, lugar que ocupamos, lugar de poder, lugar de saber. A análise da implicação traz ações, sentimentos, acontecimentos e condições que sempre nos atravessam e que muitas vezes não passam por uma questão consciente, mas problematizam nossas práticas profissionais. Ou seja, corresponde a:

Colocar em análise o lugar que ocupamos, nossas práticas de saber-poder enquanto produtoras de verdades - consideradas absolutas, universais e eternas - seus efeitos, o que elas põem em funcionamento, com o que elas se agenciam é romper com a lógica racionalista ainda tão fortemente presente no pensamento ocidental (Nascimento \& Coimbra, 2008, p. 245).

As reflexões sobre a prática institucional se efetuaram em encontros mensais de supervisão, que foram espaços de trocas e alinhamento à teoria, de aprimoramento do saber, efetuado por meio do desvelamento das manobras do instituído e da busca da possibilidade de sustentação de novas formas de atuação. A partir dessa orientação teórico-metodológica, o percurso trilhado em meio a esse campo de forças encontra-se relatado a seguir.

\section{Interferências no CREAS: discussão e resultados}

O CREAS com o qual trabalhamos possui sete profissionais da psicologia, seis profissionais do serviço social, duas auxiliares administrativas, um advogado, um motorista, uma auxiliar de serviços gerais, quatro estagiários de psicologia e uma guarda mirim alocada na recepção. O serviço está em sede própria há um ano, construída com recurso federal. O prédio atende às normas de acessibilidade e conta com três salas de atendimentos, uma brinquedoteca, uma sala ampla de reunião, uma sala para o setor jurídico e uma para coordenação, cozinha, banheiros com acessibilidade e quatro salas para os(as) técnicos(as). Essa divisão do substrato físico favorece a separação dos(as) técnicos(as) por núcleo. Os(as) técnicos(as) atendem apenas às demandas específicas de seus núcleos, o que configura uma proposta segmentada que favorece o distanciamento deles e dificulta o trabalho em equipe.

Essa separação em núcleos específicos, que existe desde o início do serviço no município, foi definida a partir do público atendido. Entretanto, não há registro que justifique esse modelo nucleado. Na época dessa experiência, contávamos com o Núcleo da Pessoa Idosa e da Pessoa com Deficiência que possui uma assistente social e duas psicólogas; o Núcleo da Mulher e Violências de Gênero, com uma psicóloga e uma assistente social; o Núcleo da Criança e Adolescente, que possui em seu corpo técnico duas psicólogas, um psicólogo e duas assistentes sociais; e o Núcleo de Medidas Socioeducativas, composto por duas assistentes sociais e uma psicóloga. A proposta do serviço nucleado, se por um lado garante profissionais atentos às demandas daquele público com clareza em suas especialidades e alinhamento em suas intervenções, por outro lado favorece a separação dos(as) técnicos(as) e dos públicos, além de não os(as) convocar para trocas frequentes e diálogos em casos complexos e frequentemente entrelaçados, devido ao isolamento dos núcleos. Dessa maneira, a configuração institucional fica fadada a profissionais que permanecem em seus mesmos lugares de atuação, na medida em que investe pouco em propostas de mudanças e mantém as práticas repetitivas e desestimulantes.

Essa foi a grande questão que problematizamos, tratando-a como um analisador, que evidenciava a contradição da manutenção de uma forma instituída de trabalho que se desvencilhava das necessidades do serviço, da equipe e dos usuários. Esse arranjo estaria mantendo a segmentação dos profissionais? A forma nucleada não impediria a promoção de trocas de saberes frente a outras violações? Se uma demanda espontânea chegar ao serviço, o(a) técnico(a) está apto a atender a uma demanda de violação com a qual não trabalha, já que não se tem controle sobre o que chega ao serviço? Como a gestão poderia favorecer uma postura crítica frente a essa cristalização de saberes e à falta de diálogos e trocas?

Com esses desassossegos como ponto de partida, examinamos a dinâmica institucional apostando em uma leitura crítica das forças institucionais, com vistas a não impor outra forma de funcionamento, mas investir na construção coletiva. Nesse contexto, decidimos escutar os(as) técnicos(as) e ouvir também suas inquietações, além de refletir sobre a proposta 
de trocas entre eles, para tornar seu trabalho mais produtivo e motivador e melhorar o atendimento ao usuário. Havíamos discutido em supervisão a possibilidade de fazer um rodízio entre os núcleos, por meio alocação de mais um(a) técnico(a) com outro público e outra experiência, para discutir com a equipe de cada um dos núcleos e viabilizar a criação de novos sentidos, estratégias e soluções. Chamamos essa proposta inicial de "Mais Um", acreditando que ela potencializaria os saberes presentes no CREAS e o trabalho em equipe, mas queríamos problematizar essa aposta com os profissionais.

$\mathrm{Na}$ reunião geral, a escuta dos(as) técnicos(as) nos trouxe os desafios dos casos atendidos, dentre eles o problema enfrentado na semana: tínhamos um compromisso com uma empresa, mas uma técnica do Núcleo da Mulher estava de férias, a outra adoeceu e a estagiária estava em uma demanda na delegacia da mulher. Era semana de prevenção à violência contra a mulher e a dupla responsável por ela deveria apresentar para esse público como se dão os atendimentos e encaminhamentos, dentre outras informações. Nesse contexto, para atender a essa demanda, precisaríamos contar com um(a) técnico(a) de outro núcleo, o que configurou uma situação-problema que nos permitiu refletir com a equipe sobre o fato de a segmentação dos(as) técnicos(as) em núcleos dificultar a fluidez do atendimento às demandas e evidenciar a necessidade de estarmos abertos para os outros núcleos. Na discussão, sugerimos o "Mais Um”, na tentativa de mudar a norma institucional de que cada um deveria trabalhar somente em seu setor. Conforme Lourau (2004), além de normas, as instituições são compostas por maneiras como os indivíduos se relacionam entre si e com as próprias instituições, motivo pelo qual acreditamos no processo contínuo de institucionalização e tentamos criar um funcionamento que possibilitasse a eclosão de forças instituintes.

Em consonância com os pressupostos das forças instituintes e formas do instituído, apontamos as contribuições das ideias de Deleuze e Guattari (1996), desta vez não a partir da dialética como promovedora das tensões da realidade, mas sim da imanência de funcionamentos diferentes que coexistem como formas e forças. Insistimos nesse diálogo para ampliar a leitura não só do analisador, mas também do processo de intervenção realizado. Os autores fazem a leitura de que o plano das formas remete ao funcionamento de codificação e é dicotômico por estabelecer métodos de hierarquização e de organização, enquanto o plano das forças é fluido e sustenta o funcionamento heterogêneo, os agenciamentos e as conexões. Nessa direção, podemos captar os processos que ocorrem na experiência do "Mais Um" pelas seguintes linhas:

as de segmentaridade dura, características dos grandes conjuntos molares ou estratos, como as classes sociais e os gêneros; as de segmentaridade maleável, caracterizadas por relações moleculares de desestratificações relativas, com velocidades acima ou abaixo dos limites da percepção, e que, ao contrário dos grandes movimentos e cortes que definem os estratos, compõem-se de elementos rizomáticos, esquizos, sempre em devir, fluxos sempre em movimento que retiram o homem da rigidez dos estratos; e as linhas de fuga, que se caracterizam por uma ruptura com os estratos ou sua desestratificação absoluta (Cassiano \& Furlan, 2013, p. 373).

Para os autores, essas três linhas constantemente se entrelaçam e interferem uma sobre as outras, funcionando por imanência (Deleuze \& Guattari, 1996). Frequentemente se transformam umas nas outras com apoio em pontos de rigidez e vice-versa. Cassiano e Furlan (2013) assinalam que o efeito de ser envolto por elas pode durar alguns instantes ou se manter por um tempo, isto é, pode ser passageiro ou ganhar maior extensão em nossas vidas. Apontam também que em cada estrato formado pelas linhas duras há conexões que favorecem linhas de fuga, forças que podem romper com o que se encontra estabelecido e que se abrem para a elaboração de novas relações.

Em uma associação a essas linhas de forças e formas, encontramos no cotidiano de trabalho da equipe no CREAS os seguintes estratos, mantidos pelo instituído: a estrutura normativa que as compõe e todos os seus atravessamentos, que é necessária para o funcionamento do equipamento, mas também contém as intercorrências, dificuldades e conflitos institucionais que fazem parte dessa trama. Dessa maneira, as linhas duras, estratificadas, apontam uma estabilidade ora necessária, ora posta como impedimento para novos arranjos. Nesse sentido, a sobrecarga de trabalho, a tendência à repetição e ao não questionamento do formato nucleado, as contestações entre os profissionais, dentre outros fatores, favoreciam a reprodução. As possíveis modificações explanadas 
nesta experiência ocorreram a partir de um diagnóstico dessas linhas, mediante o qual foi possível pensar uma saída institucional.

Em meio a queixas e lamentos, a proposta do "Mais Um" causou certo espanto e tensão em um primeiro momento, uma vez que a força do instituído espera sempre a reprodução e a manutenção do que já existe. Porém, insistimos na ideia argumentando que a curto e médio prazo gostaríamos de contar em todas as reuniões de núcleo com um membro de outro núcleo, na tentativa de criar fissuras nas linhas duras. Então, as reações foram diversas: escutamos alguns apontamentos positivos e outros negativos. O plano de organização e as formas conhecidas foram desestabilizadas e frisamos as questões institucionais e a necessidade de sair do comodismo buscando outras estratégias de funcionamento apoiadas por alguns profissionais. Assim, mantivemos a proposta de um(a) técnico(a) a mais nas reuniões de equipe por núcleo, com a ressalva de que a experiência seria avaliada pela equipe nas próximas reuniões, para discutirmos coletivamente se seria mantida ou não.

Inicialmente, idealizou-se que esse(a) técnico(a) atuaria tanto como um(a) articulador(a) e aprendiz quanto como um facilitador(a) e provocador(a), de forma que deixasse circular conhecimentos de maneira horizontal, na expectativa de convocar a transversalidade. Como apontam Simonini e Romagnoli (2018), a transversalidade foi um conceito desenvolvido por René Lourau para sustentar a horizontalidade e assim burlar as hierarquias instituídas em um grupo, em um processo que o fortifica e permite mudanças institucionais. Por outro lado, a transversalidade, segundo Félix Guattari, remete a agenciamentos, a novas possibilidades de conexões, o que pretendíamos com o “Mais Um”, pois

Sempre haverá ' $n$ ' processos de subjetivação que flutuam constantemente segundo os dados, segundo a composição dos agenciamentos, segundo os momentos que vão e vêm. E é nesses agenciamentos que convém apreciar o que são as articulações entre os diferentes níveis de subjetivação e os diferentes níveis de relação de forças molares (Guattari \& Rolnik, 2011, p. 155).
Para tentar convocar mais ainda a transversalidade, demandamos à equipe que, em suas atuações com os grupos para pais, com famílias e com mulheres em situação de violência ou rompimento, elas fossem repensadas com os(as) técnicos(as) responsáveis (um de cada núcleo) e que a leitura sobre o grupo atendido não fosse isolada e associada somente a um núcleo. Essa compreensão favorecia pensar cada usuário em suas interfaces com os núcleos e a própria política de assistência social, além de abordar o caso segundo pontos comuns que permitem o diálogo entre os profissionais; um desses pontos é a própria chegada ao equipamento acarretada pela situação de violação de direito, situação enfrentada por todos que chegam até o CREAS. Nesse momento é importante não rotular a demanda de chegada. Dessa maneira, implantamos a seguinte organização e sistematização da equipe para acompanhamento do processo: encontros quinzenais com supervisão sobre os grupos, nos quais estudamos conceitos teóricos, discutimos o funcionamento dos grupos atendidos e levantamos as demandas apresentadas nos encontros. No início desses encontros, os(as) técnicos(as) frequentemente se queixavam do grande número de desistências, das flutuações dos grupos e da não participação dos usuários, situações que os desanimavam. Embora demandada pelas intervenções na política de assistência social, percebemos que a modalidade de intervenção em grupo se distancia do modo dominante e instituído de se fazer psicologia. Barros (2009) pontua que nosso trabalho se fundamenta no modo-indivíduo de subjetivação que nasceu atrelado ao projeto da modernidade, cujo eixo central corresponde ao indivíduo e à razão. Nesse modo, está presente a noção de que no interior do sujeito se encontra sua verdade, concepção que valoriza sua dimensão privada. Nessa perspectiva, a lógica individual impera e o indivíduo é o centro de nossas intervenções. No entanto, em nossos encontros ficava clara a importância do trabalho com grupos no CREAS, que é indispensável se for bem conduzido, isto é, se fizer boas leituras e utilizar o instrumento trazido pelo próprio grupo para uma reflexão técnica que inclua a resistência desse grupo.

Considerando as consequências decorrentes da violação de direitos, é de fundamental 
importância que sejam prestados à vítima e seus responsáveis legais, assistência, apoio e incentivo necessários para a ressignificação dos fatos ocorridos, impedindo que os traumas da violência interfiram na sua vida pessoal, familiar e social. Nesse sentido, os grupos de apoio - dentre outros espaços de possibilidades de assistência às vítimas de violação de direitos - podem exercer grande importância nesse processo (Silva, Sousa, Silva Júnior, Nogueira, \& Albuquerque, 2014, p. 30).

Nos encontros da equipe, mediante as queixas relatadas acima, chegamos à conclusão de que faríamos um grupo com as famílias do CREAS, em oposição à antiga divisão entre grupo dos pais dos adolescentes de medidas socioeducativas, grupo de função protetiva e grupo para mulheres. A partir de muitos encontros de supervisão, enxergamos que há confluência das temáticas que poderíamos "trocar figurinhas"; então, novamente faríamos trocas de técnicos(as) e leituras múltiplas, para o enfretamento das formas segmentadas via outras conexões. Nesse momento, os(as) técnicos(as) já estavam participativos(as), já problematizavam a experiência do "Mais Um" e acreditavam em sua capacidade de transitar por outros públicos atendidos no serviço que se caracterizam por algo comum: a situação da violação de direito por eles vivenciada. A equipe sustentou que um olhar especializado, focado em um tipo de violação de direito, poderia fazer com que os membros das famílias ou indivíduos que ali chegassem tivessem uma leitura direcionada e fragmentada sobre sua realidade. Era preciso dialogar também entre as formações, como atesta o próprio Conselho Federal de Psicologia (2012):

De fato, as orientações técnicas sobre o trabalho no CREAS não distingue as funções dos profissionais que compõem a equipe de referência, mas consideramos que, apesar desses profissionais exercerem a mesma função, cada categoria profissional no CREAS trabalha a partir de teorias e metodologias relacionadas com a sua área de conhecimento (p. 48).

Como o serviço ofertado deve promover o rompimento da violência, providenciar aos usuários encaminhamentos aos serviços da rede assistencial ou demais órgãos públicos e estimular a mobilização comunitária, a troca dos(as) técnicos(as) se faz necessária por viabilizar maior compreensão e melhor condução dos casos.

A proposta do "Mais Um" foi implantada no CREAS no mês seguinte a sua discussão e proporcionou muitos os deslocamentos institucionais. Nessa reunião de equipe, apresentamos um quadro com todos os horários das discussões de cada núcleo e os(as) técnicos(as) puderam escolher em qual deles queriam contribuir na figura do "Mais Um". Profissionais desmotivados e resistentes se tornaram curiosos por conhecer as especificidades e os processos de outros. Nas reuniões de núcleos, o(a) técnico(a) a mais se interessava em contribuir e na maioria das vezes apontava que não só ele, como também os demais do núcleo necessitavam participar dos casos. Na gestão, víamos como a experiência estava sendo rica, com fortes vivências de troca. Para ir além de nossas percepções, demandamos um retorno semanal da equipe sobre o processo.

Os(as) próprios(as) técnicos(as) que tiveram a experiência passaram a avaliá-la como produtiva e inclusive trouxeram a experiência de uma demanda espontânea que chegou para o Núcleo da Pessoa Idosa e que, na falta dos(as) técnicos(as) desse núcleo, a técnica do Núcleo da Criança fez a acolhida e deu os devidos encaminhamentos. Ativos(as), os(as) técnicos(as) passaram a ter interesse em não se fecharem apenas em seu núcleo, mas terem a oportunidade de buscar novos conhecimentos, de inteirar-se de outros públicos. Decidimos a médio prazo trabalhar em esquema de rodízio, como uma possibilidade de todos estarem mais próximos uns dos outros e abertos a outros núcleos.

Nesse processo, a equipe tornava-se mais participativa e mais coesa, mas ainda havia dificuldades com o Núcleo da Pessoa Idosa, pois ele envolve uma demanda intensa, casos muito complexos, respostas ao Ministério Público, reuniões com a rede socioassistencial, poucos profissionais no núcleo, dentre outros fatores. Era o momento de transversalizar o "Mais Um" em seus efeitos. Afinal, o processo de participação de técnicos(as) nas reuniões de núcleo aprimorava seu olhar sobre os desafios dos colegas, as intervenções com as famílias e a construção do método de trabalho, além de desenvolver uma escuta do fazer do próximo, em uma colaboração efetiva com o processo. Na participação da 
discussão do núcleo dos colegas, havia contribuições dos(as) técnicos (as) participantes, cujas sugestões contemplavam vivências de suas experiências, trocas e soluções advindas de seus núcleos de origem. O olhar da gestão diante desses encontros foi captado pela potência do novo, pelas outras formas de organização da equipe, novos interesses dos(as) técnicos(as), pela troca de saberes. Em momentos de autogestão, a própria gestão se desloca, ou seja, altera seu posicionamento hierárquico, com abertura para decisões coletivas e receptividade das ideias da equipe. São sustentados novos arranjos institucionais, mais coletivos e participativos, pois próprios membros da equipe levantaram soluções que deslocam o plano das formas para a intensidade das forças do coletivo. Os profissionais passam a fazer análises críticas frente a seus posicionamentos e intervenções e a juntos buscar saídas para os impasses, por meio de linhas de fuga que rompem com o instituído e abrem a possibilidade de a força instituinte aflorar.

A possibilidade de contribuição dos(as) técnicos(as) com o Núcleo da Pessoa Idosa adveio de uma baixa demanda de encaminhamentos do Poder Judiciário para atendimentos no Núcleo de Medidas Socioeducativas. Com essa situação, técnicos(as) deste último núcleo poderiam atender à demanda reprimida do primeiro núcleo. Na ocasião, prontamente duas técnicas se colocaram à disposição para colaborar nos atendimentos e outra se ofereceu para contribuir com a construção da metodologia. Em seus movimentos, os(as) técnicos(as) produziam novos agenciamentos. Transitavam com seus saberes, entre os adolescentes em cumprimento das medidas socioeducativas e entre as pessoas idosas; incorporaram outro formato de trabalho, apontaram dinâmicas facilitadoras, trouxeram suas experiências em visitas e contribuíram com a metodologia de trabalho. Posteriormente, uma dessas técnicas teve sua mudança definitiva para o trabalho direto com as pessoas idosas, a fim de contribuir ainda mais com os desafios enfrentados por esse núcleo; vale apontar que se trata de uma decisão da própria técnica.

Presenciamos movimentos autônomos em um território antes enrijecido e segmentarizado, alterações na forma dos(as) técnicos(as) relacionarem-se entre si e com seu saber, a disponibilidade de trocas entre os núcleos e o avanço das metodologias de trabalho e de intervenção com as famílias. Esse processo refletiu nos usuários devido à maior fluidez nos atendimentos e à maior sustentação do compromisso da equipe com a política de assistência social. Em um texto no qual Lima e Yasui (2014) refletem acerca das práticas de atenção psicossocial no campo da saúde, os autores afirmam: "No entanto, não há vida sem movimento e criação e, portanto, é preciso apropriar-se da tradição, destruí-la para que algo novo advenha. $\mathrm{O}$ novo surge e busca-se articulá-lo a uma rede coletiva de sustentação, criando novos territórios" (p. 602). Concordamos com essa afirmação, desta vez aplicada ao campo da assistência social e a partir de nossa experiência.

\section{Considerações finais}

A partir do referencial institucionalista, examinamos neste texto o analisador "a separação dos(as) técnicos(as) por núcleo". Essa situação nos permitiu refletir acerca do contexto institucional, das relações entre os técnicos, da força de poder da gestão e das relações com os usuários, que promovem deslocamentos nas práticas da equipe, em seu protagonismo e em sua autonomia. Esse processo nos fez transitar entre o modo-indivíduo e a força do coletivo. A mudança na participação e no empenho dos profissionais fez parte desse percurso, de modo que o trânsito de informações circulou de forma mais efetiva e contributiva, configurando uma nova postura que afetou os indivíduos e famílias atendidos pelo serviço. Quanto à gestão, acreditamos que a leitura institucional favoreceu nossa saída do âmbito pessoal, na medida em que nos tornamos atentos a nossa implicação, isto é, a nosso lugar de poder, que pode atuar não só como opressor, mas também com intercessor, como um vetor de outras formas de intervir e de se relacionar em equipe.

Esperamos, com a partilha de nossa experiência, contribuir para a reflexão da atuação dos psicólogos nas equipes do CREAS. Nessa direção, acreditamos que a dinâmica de mudanças sustentadas por forças instituintes advém das construções coletivas que possibilitem aos profissionais que atuam nesse contexto o protagonismo nesses processos. Muitas vezes esses agentes precisam criar desestabilizações em formas cristalizadas e naturalizadas de atuar, para que novas estruturas de funcionamento institucionais, partilhadas nessa experiência, possam dar passagem a forças instituintes. 


\section{Referências}

Barros, R. B. de. (2009). Grupo: a afirmação de um simulacro. Sulina; UFRGS.

Cassiano, M., \& Furlan, R. (2013). O processo de subjetivação segundo a esquizoanálise. Psicologia \& Sociedade, 25(2), 373-378. http://www.scielo.br/scielo.php?script=sci_arttext\&pid=S0102-71822013000200014\&lng=en\&tlng=pt

Conselho Federal de Psicologia. (2012). Referências técnicas para prática de psicólogas(os) no Centro de Referência Especializado da Assistência Social - CREAS.

Deleuze, G., \& Guattari, F. (1996). Micropolítica e segmentaridade. In G. Deleuze \& F. Guattari, Mil Platôs: capitalismo e esquizofrenia (pp. 83-115). Editora 34.

Florentino, B. R. B., \& Melo, W. (2017). A inserção da psicologia no Sistema Único de Assistência Social: notas introdutórias. Gerais: Revista Interinstitucional de Psicologia, 10(1), 3-12. http://pepsic.bvsalud.org/scielo. php?script=sci_arttext\&pid=S1983-82202017000100002\&lng=pt\&tlng=pt

Guattari, F. (1993). Guattari, o paradigma estético [Entrevista concedida a Fernando Urribarri]. Cadernos de Subjetividade, 1(1), 29-34.

Guattari, F, \& Rolnik, S. (2011). Micropolítica: cartografias do desejo. Vozes.

Lima, E. M. F. de A., \& Yasui, S. (2014). Territórios e sentidos: espaço, cultura, subjetividade e cuidado na atenção psicossocial. Saúde em Debate, 38(102), 593-606. https://dx.doi.org/10.5935/0103-1104.20140055

Lourau, R. (1980). El estado e el insconsciente: ensayo de sociología política. Kairós.

Lourau, R. (2004). Objeto e método da Análise Institucional. In: S. Altoé (Org.), René Lourau: analista institucional em tempo integral (pp. 66-86). Hucitec.

Macedo, J. P., Sousa, A. P., Carvalho, D. M., Magalhães, M. A., Sousa, F. M. S., \& Dimenstein, M. (2011). O psicólogo brasileiro no SUAS: quantos somos e onde estamos? Psicologia em estudo, 16(3), 479-489. http://dx.doi. org/10.1590/S1413-73722011000300015

Marques, C. F., Roberto, N. L. B., Gonçalves, H. S., \&Bernardes, A. G. (2019). O que significa o desmonte? Desmonte do que e para quem? Psicologia: Ciência e Profissão, 39(n.spe2), 6-18. https://doi.org/10.1590/1982-3703003225552

Ministério do Desenvolvimento Social. (2017). Curso de Atualização sobre a Organização e Oferta dos Serviços de Proteção Social Especial. https://setades.es.gov.br/Media/seadh/Capacita\%20SUAS/Caderno_do\%20Aluno.pdf

Ministério do Desenvolvimento Social e Combate à Fome. (2011). Perguntas e Respostas: Centro de Referência Especializado de Assistência Social - CREAS.

Nascimento, M. L., \& Coimbra, C. M. B. (2008). Análise de implicações: desafiando nossas práticas de saber/poder. In A. R. Geisler, A. L. Abrahão \& C. M. B. Coimbra (Orgs.), Subjetividade, violência e direitos humanos: Produzindo novos dispositivos na formação em saúde (pp. 143-153). EDUFF.

Raichelis, R., \& Nery. V. (2014). A inserção do assistente social e do psicólogo no SUAS: uma contribuição ao debate. In R. C. Romagnoli \& M. I. C. Moreira (Orgs.), SUAS: Sistema Único de Assistência Social: A articulação entre psicologia e o serviço social no campo da proteção social, seus desafios e perspectivas (pp. 211-234). Editora CRV.

Ribeiro, A. B., Paiva, I. L., Seixas, P. S., \& Oliveira, I. M. F. F. (2014). Desafios da atuação dos psicólogos nos CREAS do Rio Grande do Norte. Fractal: Revista de Psicologia, 26(2), 461-478. https:// dx.doi.org/10.1590/1984-0292/421

Romagnoli, R. C. (2014). O conceito de implicação e a pesquisa-intervenção institucionalista. Psicologia \& Sociedade, 26(1), 44-52. https://dx.doi.org/10.1590/S0102-71822014000100006

Silva, J. B., Vasconcellos, P. A., \& Figueiredo, V. C. N. (2018). Trabalho e sofrimento: desafios da saúde mental de profissionais da assistência social. Psicologia Em Estudo, 23, 69-79. https://doi.org/10.4025/psicolestud.v23i0.39108

Silva, L. B., Sousa, D. V. L., Silva Júnior, E. G. da, Nogueira, J. de A., \& Albuquerque, L. A. F. P. (2014). Direitos violados e grupos de apoio: intervenções logoterápicas com responsáveis de adolescentes usuárias do Centro de Referência Especializado de Assistência Social. Revista Logos \& Existência, 3(1), 28-42. http://www.periodicos. ufpb.br/ojs/index.php/le/article/download/19239/11480

Simonini, E., \& Romagnoli, R. C. (2018). Transversalidade e Esquizoanálise. Psicologia em Revista, 24(3), 915-929. https://doi.org/10.5752/P.1678-9563.2018v24n3p915-929 


\section{Caroline de Souza}

Doutoranda em Psicologia pela Pontifícia Universidade Católica de Minas Gerais (PUC-Minas), Belo Horizonte-SP. Brasil. Mestre em Psicologia pela Pontifícia Universidade Católica de Minas Gerais (PUC-Minas), Belo Horizonte-SP. Brasil. Atuante no Sistema Único de Assistência Social.

E-mail: carolinedesouzapsi@yahoo.com.br

(D) https://orcid.org/0000-0002-8398-4951

\section{Roberta Carvalho Romagnoli}

Psicóloga e Mestre em Psicologia Social pela Universidade Federal de Minas Gerais (UFMG), Belo Horizonte - MG. Brasil. Doutora em Psicologia Clínica pela Pontifícia Universidade Católica de São Paulo (PUC-SP), São Paulo - SP. Brasil. Pós-doutora em Análise Institucional pela Universidade Cergy-Pontoise. França. Professora do programa de Pós-graduação em Psicologia da Pontifícia Universidade Católica de Minas Gerais (PUC-Minas), Belo Horizonte - SP. Brasil. Pesquisadora do CNPQ e da FAPEMIG.

E-mail: robertaroma1@gmail.com

(1) https://orcid.org/0000-0003-3551-2535

Endereço para envio de correspondência:

Pontifícia Universidade Católica de Minas Gerais. Programa de Pós-Graduação em Psicologia. Av. Itaú, 525, Bairro Dom Cabral. CEP:30535-012. Belo Horizonte - MG. Brasil.

Recebido 04/04/2019

Aceito 21/08/2020

Received 04/04/2019

Approved 08/21/2020

Recibido 04/04/2019

Aceptado 21/08/2020

Como citar: Souza, C., \& Romagnoli, R. C. (2021). Experiência de Gestão no CREAS em Interlocução com a Análise Institucional. Psicologia: Ciência e Profissão, 41, 1-12. https://doi.org/10.1590/1982-3703003222287

How to cite: Souza, C., \& Romagnoli, R. C. (2021). Management Experience in CREAS in Dialogue with Institutional Analysis. Psicologia: Ciência e Profissão, 41, 1-12. https://doi.org/10.1590/1982-3703003222287

Cómo citar: Souza, C., \& Romagnoli, R. C. (2021). Experiencia de Gestión en CREAS en Diálogo con el Análisis Institucional. Psicologia: Ciência e Profissão, 41, 1-12. https:// doi.org/10.1590/1982-3703003222287 